\title{
Islands of Contradiction: Presuppositional and Negative Islands
}

\author{
Márta Abrusán \\ Institut Jean Nicod (ENS, CNRS)
}

\section{Introduction}

Wh-words that range over individuals can escape weak islands, such as factive and negative islands, while $w h$-words ranging over manners or degrees cannot:

a. *How do you regret that John behaved? Factive island

b. Who do you regret that John invited?
a. *How many children don't you have?
Negative island

b. Who didn't you invite?

Fox and Hackl (2007), (partly based on Kuno and Takami 1997) have showed that negative degree islands such as (2a) above become perfectly acceptable if we place an existential modal in the scope of the negation, or a universal modal above the negation:

(3) a. How many children are you not allowed to have?

b. How many children are you required not to have?

We might observe that the same pattern obtains with negative manner questions if we place an existential modal in the scope of negation (cf. 4a). Further, attitude verbs above negation can obviate the island effect as well, as shown in (4b):
a. How was John not allowed to behave?
b. How fast do you hope that Bill did not drive?

For most speakers, factive islands can be also significantly ameliorated by placing an existential modal in the scope of a factive verb:

?How do you regret that John was allowed to behave?

This paper reports some results of my MIT Ph.D. dissertation: Special thanks to my thesis advisor Danny Fox, and my thesis committee: Gennaro Chierchia, Irene Heim, David Pesetsky, as well as to Benjamin Spector, to whom I owe the crucial suggestion to use the interval based semantics for degrees in the context of negative degree islands. Thanks also to Emmanuel Chemla, Jon Gajewski, Roni Katzir, Giorgio Magri and Anna Szabolcsi as well as to Vincent Homer, Nathan Klinedinst, Winfried Lechner, Øystein Nilsen and Philippe Schlenker, and the audiences at SALT 18, ZAS Berlin and the EGG Summerschool in Debrecen for many helpful comments, questions and suggestions. I would like to acknowledge financial support by the European Science Foundation (Euryi project on presupposition, to P. Schlenker) and Collegium Budapest. All remaining errors are my own. 
These facts pose a serious challenge for any account that argues that the intervention is caused by some syntactic property of negation or factive verbs (cf. the Relativised Minimality of Rizzi 1990 and much subsequent work), because it is rather unclear why adding an extra structural element such as a modal or an attitude verb should be able to obviate any syntactic intervention creating property that negation and factives might have. Further, we also need an explanation as to why precisely these modals and attitude verbs create the obviation effects, but not others. Universal modals in the scope of negation e.g. do not create obviation, as shown below (cf. also Fox and Hackl 2007):

*How fast is John not required to drive?

It seems then that a semantic account for the island effects created by factives and negation is simply inevitable.

Interestingly enough however, despite a number of semantic proposals for weak islands, an explanation that is able to account for the different types of factive and negative islands as well as their obviation facts has not been available so far. While Szabolcsi and Zwarts $(1993,1997)$ offer a very elaborate account for intervention created by quantifiers and negation, their proposal for factive islands remains somewhat tentative. Neither do they notice the obviation facts discussed above, and hence they do not offer any explanation for them either. Honcoop's (1998) proposal is tailored for the Germanic what-for split, and is not clear that it is extendable to classic islands nor the obviation facts. At the same time, negative degree islands have enjoyed a great deal of specialized attention (Rullmann 1995, Fox and Hackl 2007), the latter offering an ingenious solution for the obviation problem in the case of negative degree questions as well, yet it has remained unclear whether these accounts can be extended to negative islands that arise with other extractees (e.g. islands created by manners), or to other types of islands, e.g. islands created by factives. Indeed Rullmann (1995) expresses skepticism that such a unified account is at all possible. Fox (2007) laid out a blueprint as for the conditions that an analysis of negative islands created by manner questions would have to fulfill, but himself does not provide such an analysis, nor does he discuss the case of factive islands. Finally, we might mention Oshima (2006), who proposed a partial account for certain cases of factive islands, yet his account does not extend to factive islands with degree questions, nor to the negative islands nor the obviation facts.

The present paper proposes a new semantic account for factive and other presuppositional islands that is easily extendable to negative islands as well. The central claim I make is that these islands arise because they are predicted to lead to a contradiction at some level. It is proposed that factive islands arise because manner and degree questions - but not questions about individuals — stand with a presupposition that is contradictory. As no context can entail a contradictory set of propositions, these questions always lead to presupposition failure. In the case of negative islands a contradiction arises in a different manner: I will observe that in these questions the condition according to which questions must have a unique most informative answer (cf. Dayal 1996) cannot be met. Therefore, any complete 
(exhaustive) answer to such questions is bound to state a contradiction. I argue that the reason why a contradiction arises in the case of manner and degree islands is based on two independently motivated assumptions about the domain of manners and degrees ${ }^{1}$. The first is that the domain of manners contains contraries. The second is that degree predicates relate individuals to intervals (cf. Schwarzschild and Wilkinson 2002, Heim 2006). Thus according to this proposal the compositional semantics of questions supplies everything we need for the explanation of presuppositional and negative questions, without invoking any further special rules. The paper makes a couple of further novel empirical claims as well. I propose that the account for factive islands can be extended to other islands created by presuppositional items: extraposition islands, and certain adverbial interveners. I also notice the fact that we can observe a correlation between presupposition strength and the strength of islandhood: I show that this is the case in the case of extraposition islands and adverbial interveners.

\section{Presuppositional Islands}

\subsection{Presuppositions of Questions: Questions about Individuals}

In this section it is observed that questions which contain a variable in the scope of a factive item are naturally understood in a way which suggests that their presupposition projects in a universal manner. I also discuss certain apparent counterexamples to this generalization, and argue that in these cases we are in fact dealing with a special type of identity questions, in the case of which the presupposition projected is simply invariant.

Let's start by examining questions about individuals containing a variable in the scope of a factive verb such as regret:

Who among these ten people does Mary regret that Bill invited?

Heim (1992) has argued that $x$ regrets that $p$ triggers the presupposition that $\mathrm{x}$ believes that $\mathrm{p}$. In other words the presupposition of regret requires that every belief world of the subject is such that it entails p. Given this, the denotation of the question above will look as follows:

II (7) $\rrbracket^{\mathrm{w}}=\lambda \mathrm{p} . \exists \mathrm{x}\left[\mathrm{x} \in\{\right.$ these ten people $\} \& \mathrm{p}=\lambda \mathrm{w}^{\prime}$. Mary regrets that Bill invited $x$ in $\left.w^{\prime}\right]$

What does the question in (7) presuppose? Empirically, it seems to presuppose that for every $\mathrm{x}$ in the given domain, Mary believes that Bill invited $\mathrm{x}$. We observe then that the projection pattern with factive verbs is universal. In the case of a question about individuals the context can easily satisfy the set of

${ }^{1}$ Similarly to Sz\&Z, I will not dicuss islands that arise with why-questions. The reason for this is that there is independent evidence that why-adjuncts in fact independently favor late insertion/ high attachment in the structure, cf. e.g. Ko (2005). 
presuppositions that the question has because the presuppositions of the alternatives are independent from each other. Note also that similar data about universal projection in constituent questions were observed in Guerzoni (2003) ${ }^{2}$.

The universal projection seems also to be at the heart of the contrast discovered in Szabolcsi and Zwarts (1993) between questions about individuals with a predicate that can be iterated vs. questions that contain one time only predicates:

(9) a. To whom do you regret having shown this letter?

b. *From whom do you regret having gotten this letter?

Observe that the difference between the two questions above can be easily explained under the assumption that indeed the projection pattern of the presuppositions is universal. Given such a pattern, the example in (9a) presupposes that you have shown the letter to a number of people-which is an unproblematic presupposition. According to the universal projection pattern, the example in (9b) will likewise presuppose that you have gotten this letter from a number of people: This condition however is impossible to meet, since get is a one time only predicate, and (on the distributive reading that we are after here) it is only possible to get a letter from a single sender. In other words, the problem with (9b) stems from the fact that it stands with a presupposition that is impossible for any context to satisfy.

Interestingly, in certain cases it is possible to obviate the above effect:

Who is the one that you regret having gotten this letter from?

This example is grammatical, despite the one-time only predicate contained in the question. Why should that be? First observe that the question above is understood as an identity question, in other words it is concerned about the identity of a particular individual, one that is already salient in the context.

(11) a. $\lambda p \cdot \exists x\left[p=\lambda w^{\prime} \cdot x=1 y\right.$. you regret that you got the letter from $y$ in $\left.w^{\prime}\right]$

b. 'For what $x, x=1 y$ such that you regret you got the letter from $y$ ?'

Since the identity question contains a definite description, now in fact we have two presuppositions embedded in each other: the uniqueness presupposition of the definite description, and the factive presupposition triggered by regret:

(12) Who is [uniqueness pres the one that you [factive pres regret having gotten this letter from]]?

${ }^{2}$ As Anna Szabolcsi (pc.) pointed out to me, we find weaker presupposition projection pattern with certain predicates such as stop smoking:

(1) Which of your friends has stopped smoking?

However, we might observe that predicates such as stop smoking are independently known to be weak triggers:

(2) I notice you are chewing on your pencil. Have you recently stopped smoking? (example due to B. Geurts) 
Moreover, we might observe that the factive presupposition trigger is in the restrictor of the definite description, as shown below:

the one [ that you factive pres regret having gotten this letter from] is Bill

However, it is an independently known fact that presuppositions embedded in restrictors of quantifiers project weakly or not at all (cf. Schlenker 2006). This can be observed in examples such as the one in (14) below, which does not seem to stand with the inference that all of these ten boys are incompetent:

(of these 10 boys) No one [who is aware that he is incompetent] applied

In the case of (10) then the factive presupposition that is embedded in the restrictor of the definite description fails to project, and it is only the uniqueness presupposition of the definite description that projects. Since the uniqueness presupposition is invariant, the question itself will only presuppose that there is a unique individual which you regret having gotten the letter from. This presupposition in turn can be easily satisfied in any context, and hence the question is acceptable.

\subsection{Presuppositional Islands with Factive Verbs 1: Questions about Manners}

Similarly to one time only predicates, manner questions that contain a variable in the scope of the factive verb are predicted to always stand with a contradictory set of presuppositions. As there can be no context that satisfies the presupposition of these questions, they always result in a presupposition failure.

The crucial assumption that I would like to introduce is that the domain of manners always contains contraries. The observation that predicates have contrary oppositions dates back to Aristotle's study of the square of opposition and the nature of logical relations. (cf. Horn (1989) for a historical survey and a comprehensive discussion of the distinction btw. contrary and contradictory oppositions, as well as Gajewski (2005) for a more recent discussion of the linguistic significance of contrariety). Contrariety is relation that holds between two statements that cannot be simultaneously true, though they may be simultaneously false. A special class of contraries are contradictories, which not only cannot be simultaneously true, but they cannot be simultaneously false either. Natural language negation is usually taken to yield contradictory statements (cf. e.g. Horn 1989). I will claim that every manner predicate has at least one contrary in the domain of manners (which is not a contradictory). Further, the context might implicitly restrict the domain of manners, just as the domain of individuals, but for any member in the set $\left\{\mathrm{P}, \mathrm{P}^{\prime}\right\}$, the other two members are alternatives to it in any context. Some examples of such pairs are \{wisely, unwisely\}, \{fast, slowly\}, \{by bus, by car\}, etc.

Given the simple and rather natural assumption that the domain of manners always contains contraries, manner questions that contain a factive verb are predicted however to presuppose a contradiction. Let's look at the example below: 
Since the alternative propositions in the $\mathrm{H} / \mathrm{K}$ denotation of the question range over a set of manners that contains contraries, a universal projection pattern for the presupposition embedded in the question predicts that the question presupposes a set of propositions that are contradictory:

(16) $\llbracket$ How does Mary regret that John fixed the car? $\rrbracket^{\mathrm{w}}$ $=\lambda \mathrm{p} \cdot \exists \alpha\left[\alpha \in \mathrm{D}_{\mathrm{M}} \& \mathrm{p}=\lambda \mathrm{w}^{\prime}\right.$. Mary regrets that John fixed the car in $\alpha$ in $\left.\mathrm{w}^{\prime}\right]$

(17) Projected presupposition of the question in (15):

for every manner $\alpha \in \mathrm{D}_{\mathrm{M}}$ : M. believes that J. fixed the car in $\alpha$ for every manner $\alpha \in \mathrm{D}_{\mathrm{M}}$ : M. believes that J.'s car fixing event $\mathrm{e}^{*}$ was in $\alpha$

Recall that manner questions are understood as asking about a particular event, which in this case means that the proposition embedded under the attitude verb is understood as describing a particular event $\mathrm{e}^{*}$. However, it is not possible for a single event to be an element of all the manners in a given domain of manners, because these domains always contain contraries, as it was argued above. Therefore it is not possible for John to have fixed the car in all the ways given in the context, and as a consequence the question in (15) will always presuppose that Mary has an incoherent set of beliefs.

Interestingly, the island violations above can be improved. The first way to improve these questions is shown by the examples below:

What is the manner in which John regrets that Mary fixed the car?

Such examples are often described as involving D-linking, which tends to improve the acceptability of weak islands. What I would like to suggest is that in these cases again we are dealing with identity questions, the denotation of which can be represented as below ${ }^{3}$ :

(19) $\lambda p . \exists \alpha\left[\alpha \in D_{M} \& p=\lambda w^{\prime}: \alpha=1 \beta\right.$ s.t. M regrets that J fixed the $\operatorname{car}$ in $\beta$ in $\left.w^{\prime}\right]$ 'For what manner $\alpha, \alpha=1 \beta$ such that M regrets that J fixed the car in $\beta$ ?'

The factive presupposition is again embedded in the restrictor of the definite description:

$$
\text { the manner [ such that M. regrets that J. fixed the car that way] is a }
$$

\footnotetext{
${ }^{3}$ Note that this explanation for the D-linking effect is dependent on there being a syntactic difference between the D-linked and the non-D-linked questions, i.e. it depends on the presence of the definite description at LF. I am therefore lead to assume that the LF representation even of the examples (if they indeed exist) in which a D-linking effect can observed without an overt definite description is in fact similar to that in (19), in other words that they contain a covert definite description.
} 
Since the projection pattern from the restrictors of quantifiers is very weak, as discussed e.g. in Schlenker (2006), the embedded factive presupposition will not project, only the presupposition of the definite description, which is invariant. Therefore the presupposition that the question stands with is not contradictory. Finally, note that the explanation for the above example remains the same for an analogous question with a resumptive NP, such as the one below:

(21) What is the manner such that John has fixed the car that way?

The second way of ameliorating factive island violations is by existential modals: as it was mentioned in the introduction of this paper, for most speakers, factive islands can be significantly ameliorated by placing an existential modal in the scope of a factive verb:

?How do you regret that John was allowed to behave?

Indeed the present approach predicts that a modal in the scope of a factive should ameliorate factive islands. The reason is that now the projected presuppositions are in fact not contradictory. Consider the question in (22) above: This question only stands with the presupposition that for every manner, John was allowed to behave in that manner, which is not a contradictory set of propositions. Since the set of propositions that the question presupposes is not contradictory, the context can easily satisfy it, and therefore the question is acceptable.

\subsection{Presuppositional Islands with Factive Verbs 2: Degree Questions ${ }^{4}$}

The crucial tenet on which the explanation of the island sensitivity of degree islands rests is the idea that degree questions range over intervals. In other words, following the proposals advanced in Schwarzschild and Wilkinson (2002) and Heim (2006). I will assume that degree predicates denote relations between individuals and intervals (sets of degrees), as shown in (23). Given this, the denotation of a degree question will be as in (24):

$$
\begin{aligned}
& \llbracket \text { tall } \rrbracket=\lambda \mathrm{I}_{<\mathrm{d}, \downarrow>} . \lambda \mathrm{x}_{\mathrm{e}} . \mathrm{x}^{\prime} \mathrm{s} \text { height } \in \mathrm{I} \\
& \text { [How tall is John? } \rrbracket^{w}=\lambda p . \exists I\left[I \in D_{I} \wedge p=\lambda w^{\prime} \text {. John's height } \in I \text { in } w^{\prime}\right]
\end{aligned}
$$

Now the denotation of a degree question that contains a factive predicate can be represented as follows:

$$
\begin{aligned}
& \llbracket{ }^{*} \text { How tall do you regret that you are? } \rrbracket^{w}= \\
& \lambda p . \exists I \in D_{I}\left[p=\lambda w^{\prime} \text {. regret }(\lambda w " \text {, your height } \in I \text { in w', })\left(w^{\prime}\right)\right] \\
& \text { 'For what interval I, you regret that your height is in I' }
\end{aligned}
$$

${ }^{4}$ The idea to use the interval semantics for degrees was originally suggested to me by Benjamin Spector (pc.) in the context of negative islands, cf. also Section 3.2 and Abrusán and Spector (2008). 
Observe that any domain of degrees that has at least 2 degrees in $\mathrm{it}^{5}$ will contain two non-overlapping intervals, which can be pictured as follows.

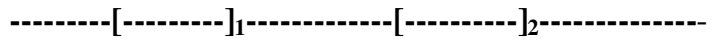

Given the universal projection pattern, the question stands with the following presupposition:

(27) Presupposition of (25): $\forall \mathrm{I} \in \mathrm{D}_{\mathrm{I}}$ : you believe( $\lambda \mathrm{w}^{\prime}$.your height $\in \mathrm{I}$ in $\left.\mathrm{w}^{\prime}\right)$ (w) 'you believe your height to be contained in every interval'

However, since the domain of degrees always contains two non-overlapping intervals, this presupposition amounts to requiring that the subject have a contradictory set of beliefs, because it is not possible that someone's height be contained in two non-overlapping intervals. Since the question stands with a contradictory presupposition, it is infelicitous in any context and hence unacceptable. A similar problem arises in the case of the narrow scope reading of how many questions, but not in the case of the wide scope reading. As I show in Abrusán (2007) this is why in the case of how many questions that contain a factive verb only the wide scope reading is available. ${ }^{6}$

\subsection{Extensions}

In this section I argue that the reasoning presented above for factive verbs can be extended to certain islands created by extraposition and certain adverbial interveners as well as some quasi-factive verbs (part-time triggers).

2.4.1. Extraposition and factives seem to belong to the same class of interveners (cf. also Honcoop 1998). This is because whether or not extraposition creates weak islands depends on the factivity of the verb/noun involved in the construction. When the extraposition is based on a noun/adjective that triggers a factive inference, the extraposition creates a weak island context. However, on the occasions that extraposition is not based on an adjective that has a factive inference, it does not give rise to weak islands either. The example in (28) below clearly stands with a factive inference that (the speaker believes that) $p$ :

\footnotetext{
${ }^{5}$ I assume that if a domain of degrees only has a single degree in it, the question will be infelicitous since it will always denote a tautology.

${ }^{6}$ It has been argued that the class of verbs that create weak islands also includes response stance verbs, e.g. deny, verify, admit, confirm, accept, acknowledge (cf. Szabolcsi and Zwarts 1993 and references therein). These verbs might be argued to be presuppositional in the sense that they "presuppose that their complements express assumptions or claims held by someone possibly other than the speaker which are part of the common ground" (Honcoop 1998: 167). Unfortunately, the fact that these verbs should create weak islands is not predicted by the present account. This is because the existential quantifier in the presupposition it should obviate the island effect. I suspect that the problem has to do with the notoriously complex and often problematic interaction of presupposition projection with existential quantification. Yet, a detailed analysis of this issue will have to wait for another occasion.
} 
It was a surprise that John behaved politely presupposes: (the speaker believes that) John behaved politely

Accordingly, the question based on this extraposition structure is predicted to be an island violation, which is indeed the case as shown by the example below:

*How was it a surprise that John behaved?

The reasoning of course is the same as the one presented for factive verbs in the previous section: the question is predicted presuppose the conjunction of the presuppositions of the alternatives in the $\mathrm{H} / \mathrm{K}$ denotation. However, as we have seen above, this set will always contain propositions that are mutually incompatible. Hence the set of presuppositions that the question stands with is always incoherent, therefore the question cannot be asked in any context.

In contrast, observe that certain other structures that can be classified syntactically as belonging to the class of extrapositions, do not stand with a factive inference?:

(30) a. It is possible that John behaved politely.

$\rightarrow$ does not presuppose that John behaved politely

b. It is dangerous for youngsters to drink wine at the party.

$\rightarrow$ does not presuppose that youngsters drink wine at the party.

Correspondingly, as one can observe by looking at the examples in (31) below, such extrapositions do not induce weak islands either.

(31) a. How is it possible that John behaved?

b. How much wine is it dangerous to drink at a party?

The questions above are acceptable, as predicted by the present theory, because they do not stand with any conflicting presuppositions, in fact probably they do not trigger any presupposition at all.

2.4.2. If the intervention by factive verbs and (factive) extraposition islands is indeed the result of the factive inference, we should find cases where the presence or absence of this inference correlates with the island creating behavior of the intervener. We do indeed find such examples in the case of certain adverbial interveners which might trigger a factive-like inference in some but not other contexts. When the lexical content together with the context suggests a factive inference, we observe island inducing behavior, but not otherwise.

Pertinent examples are provided by the adverbial interveners such as fast

${ }^{7}$ The one exception in the literature to the above claim is the following example:

(3) *How is it time to behave?

I do not have an explanation for this fact. Also, modal obviation seems for some reason to be harder in the case of extraposition islands, cf. e.g. ???How was it a surprise that John was allowed to behave? 
or twice. In these cases the presence or absence of the factive inference correlates with the island creating behavior of the intervener. This also means that I propose that adverbial interveners in fact belong to the group of presuppositional islands. This is in contrast with most (indeed, all) of the literature on this topic, who claim that (quantificational) adverbial interveners argue for treating weak island intervention in terms of scope (e.g. Kiss 1993, de Swart 1992, Szabolcsi and Zwarts 1993, Honcoop 1998). However, I believe that rather than scope restrictions, the real culprit is again presuppositions. Simons (2001) and Schlenker (2006) note that adverbs give rise to "quasi-presuppositions", i.e. in some circumstances they create inferences that project in a presupposition-like fashion:

$$
\text { Bill ran fast } \rightarrow \text { Inference: Bill ran }
$$

The projection properties of this inference seem to pattern with that of real presuppositions, at least in some circumstances, which argues that the inference is indeed a presupposition, (cf. Chemla 2007):

a. None of these ten boys ran fast $\rightarrow$ Inference: all of these ten boys ran

b. None of these ten boys solved the exercise twice.

$\rightarrow$ Inference: all of these ten boys solved the exercise

However, not all adverbs seem to behave in the same way: the adverb carefully, e.g. seems to project rather weakly, if at all:

\section{None of these ten boys searched the bags carefully ??? $\rightarrow$ everyone searched the bags}

The curious fact that we can observe now is that the projection facts above seem to correlate with the island inducing behavior of the adverbs above. In particular, observe that quantificational adverbs such as twice and adverbs such as fast, which seemed to stand with a factive presupposition above, are also robust interveners in split constructions (cf. de Swart 1992).

a. *Combien as-tu beaucoup/souvent/peu/rarement consulté de livres? How many have you a lot/often/a little/ rarely consulted of books

b. *Combien Marie a-t-elle vite mangé de gateaux? How many Marie has-she fast ate of cakes

However, the adverb carefully e.g., which shows a weak presuppositional behavior, does not induce a weak island effect (cf. Obenauer 1984):

?Combien le douanier a-t-il soigneusement fouillé de valises?

How-many the customs-officer has-he carefully searched the suitcases

It seems then that quantificational adverbs and some other adverbs like late, fast, 
etc. are more prone to triggering a "quasi-presupposition" than other adverbs: e.g. carefully does not seem to trigger a presupposition in the same fashion. Consequently, the former but not the latter seem to provoke intervention. The difference that we can observe between the various adverbs is probably triggered not so much by the particular adverbs themselves, but rather by the interaction of the context and the content of the whole sentence. And while such "quasipresuppositions" are not yet well understood, given their (quasi-) factive inference, the explanation why wh-constructions that contain adverbs are sensitive to weak islands is very similar to what we have seen above in the case of factive and extraposition islands. Further, as adverbs do not seem to be uniform in the strength of the quasi-presupposition they invoke, this analysis has the ability to predict a certain amount of variation with respect to individual adverbs, which is a welcome result.

\section{Negative Islands}

This section sketches an explanation for the oddness of negative islands, such as (37a) and (37b). These examples contrast with the one in (37c), which shows that a $w h$-word ranging over individuals can escape negation without any problems.
a. *How didn't John behave at the party?
b. *How many children doesn't John have?
c. Who didn't John invite to the party?

I propose that the reason for the unacceptability of (37a) and (37b) is that they cannot have a maximally informative true answer ${ }^{8}$. Dayal (1996) has argued that a question presupposes that there is a single most informative true proposition in the Karttunen denotation of the question, i.e. a proposition that entails all the other true answers to the question. I show that in the case of negative manner and degree questions Dayal's (1996) presupposition can never be met. As a consequence, any complete answer to these questions will amount to the statement of a contradiction.

In the case of manner questions the intuitive idea as for why these questions are bad is very simple: the domain of manners contains contrary predicates, such as fast, slow, medium speed, etc. However, as the domain of manners is structured in such a way that the predicates themselves are in opposition with each other, in the case of negative questions it will turn out to be impossible to select any proposition in the denotation of negative manner questions as the most informative true proposition. In the case of negative degree questions I argue that the maximization failure is predicted if we assume an interval-based semantics of degree constructions.

\footnotetext{
${ }^{8}$ This assumption I share with Fox and Hackl (2007). Further, this idea also related at an abstract level to the reasoning in Szabolcsi and Zwarts (1993), cf. Abrusán (2008).
} 


\subsection{Negative Islands Created by Manner Adverbials and Their Obviation}

Recall that contraries cannot be simultaneously true, but they can be simultaneously false. The fact that they can be simultaneously false means that for any pair of contraries, there will always be a set of events that do not belong to either. We might now further propose then that this set of events is itself a manner predicate. In other words for any pair of a predicate $\mathrm{P}$ and a contrary of it, $\mathrm{P}$,' there is a middle-predicate $\mathrm{P}^{\mathrm{M}}$ such that at least some of the events that are neither in $\mathrm{P}$ or $\mathrm{P}^{\prime}$ are in $\mathrm{P}^{\mathrm{M}}$. (38) summarizes the full conditions on the domain of manners:

(38) Manners denote functions from events to truth values. The set of manners $\left(D_{M}\right)$ in a context $C$ is a subset of $[\{f \mid E \rightarrow\{1,0\}\}=\wp(E)]$ that satisfies the following conditions:

i. for each predicate of manners $P \in D_{M}$, there is at least one contrary predicate of manners $\mathrm{P}^{\prime} \in \mathrm{D}_{\mathrm{M}}$, such that $\mathrm{P}$ and $\mathrm{P}^{\prime}$ do not overlap: $\mathrm{P} \cap \mathrm{P}^{\prime}=\varnothing$.

ii. for each pair $\left(\mathrm{P}, \mathrm{P}^{\prime}\right)$, where $\mathrm{P}$ is a manner predicate and $\mathrm{P}$ 'is a contrary of $\mathrm{P}$, and $\mathrm{P} \in \mathrm{D}_{\mathrm{M}}$ and $\mathrm{P}^{\prime} \in \mathrm{D}_{\mathrm{M}}$, there is a set of events $\mathrm{P}^{\mathrm{M}}$ $\in \mathrm{D}_{\mathrm{M}}$, such that for every event $e$ in $\mathrm{P}^{\mathrm{M}} \in \mathrm{D}_{\mathrm{M}} \quad\left[e \notin \mathrm{P} \in \mathrm{D}_{\mathrm{M}} \quad \&\right.$ $\left.e \notin \mathrm{P}^{\prime} \in \mathrm{D}_{\mathrm{M}}\right]$.

Given this, now we will say that the context might implicitly restrict the domain of manners, just as the domain of individuals, but for any member in the set $\{P$, $\left.\mathrm{P}^{\prime}, \mathrm{P}^{\mathrm{M}}\right\}$, the other two members are alternatives to it in any context. Observe further the surprising fact that the sentences in (39) below are odd:
a. \#John did not run fast and slowly
b. \#John did not reply wisely and unwisely

I propose that the reason for this oddness is that it is the presupposition on forming plural manner predicates $\left\{\mathrm{p}_{1}, \mathrm{p}_{2}\right\}$ that $\mathrm{p}_{1} \cap \mathrm{p}_{2} \neq 0$, and therefore e.g. the plural manner fast and slow is a presupposition failure since it is not possible for a running event to be both fast and slow at the same time, hence a plural manner cannot be formed. In fact this condition might be connected to a more general requirement that a plurality is only well formed if possible 9 .

The reason for the ungrammaticality of questions like (37a), in contrast with (37c) is that there cannot be a maximally informative true answer to a negative question about manners. Why? Let's look first at positive questions about manners. As I have suggested above, in any given context, the domain of manners might be restricted, but for any predicate of events $p$, its contrary $p$ ' and the middle-predicate $\mathrm{p}^{\mathrm{M}}$ will be among the alternatives in the H/K set. Suppose that the context restricts the domain of manners to the dimension of wisdom. Now the $\mathrm{H} / \mathrm{K}$-denotation of (40) will contain at least the propositions in (40):

${ }^{9}$ Cf. Spector (2007) and Szabolcsi and Haddican (2004) for related proposals. 
(40) a. How did John behave?

b. \{that John behaved wisely, that John behaved unwisely, that John behaved neither wisely nor unwisely

Suppose that John indeed behaved wisely. Given that the three alternatives are exclusive (as contraries cannot be simultaneously true), this means that the event in question $\left(\mathrm{e}^{*}\right)$ is an element of the set of events denoted by wisely, and not an element of any other set. Since in this case this is the only true proposition in the H/K set, Dayal's (1996) presupposition is satisfied. Note that if we had more propositions in the Hamblin set, ranging over e.g. the manners wisely, politely, and their contraries respectively, as well as the plural manners that can be formed from these, the situation would be similar to questions that range over both singular and plural individuals. Suppose that John in fact behaved wisely and politely: given the distributive interpretation of plural predicates ${ }^{10}$ this will entail that he behaved wisely and that he behaved politely, and imply that he did not behave in any other way.

Let's look now at a negative question. First imagine that our context restricts the domain to the dimension of wiseness.

a. *How didn't John behave?

b. $\lambda$ p. $\exists$ qmanner $\left[\mathrm{p}=\lambda \mathrm{w}^{\prime}\right.$. behave $\left.\left(\mathrm{w}^{\prime}\right)\left(\mathrm{e}^{*}\right)(\mathrm{John}) \wedge \neg \mathrm{q}_{\text {manner }}\left(\mathrm{w}^{\prime}\right)\left(\mathrm{e}^{*}\right)\right]$

c. \{that John did not behave wisely, that John did not behave unwisely, that John did not behave neither wisely nor unwisely\}

Suppose that John did not behave wisely was the most informative true answer. This would mean that the only set of events among our alternatives which does not contain the event in question ( $\left.\mathrm{e}^{*}\right)$ is the set of wise events. Hence the event in question is both a member of the set of events denoted by unwisely, and the set of events denoted by neither wisely not unwisely. Yet, this cannot be true, because these two sets are exclusive by definition. Therefore this cannot be the most informative true answer to (41). What about an answer such as John did not behave wisely and unwisely? This answer is ruled out by the presupposition that excludes the formation of incoherent plural manners. The predicates wisely and unwisely are contraries, and therefore they cannot form a plural manner. (As mentioned above, this is also the reason why the sentence itself is odd.) Therefore the proposition that John did not behave wisely and unwisely is not in the set of alternatives and therefore it cannot be the most informative true answer. It is easy to see that if we had more alternatives, e.g. the alternatives based on wiseness and politeness, (i.e. wisely, med-wisely, unwisely, politely, impolitely, med-politely and the acceptable pluralities that can be formed based on these) the situation would be similar: Any answer that contains only one member of each triplet leads to contradiction, and any answer that contains more than one member of each triplet

${ }^{10} \mathrm{I}$ assume that plural manner predicates combine with a distributive operator. Notice that this operator carries a homogeneity presupposition, which is crucial in the case of negative questions. 
is a presupposition failure. There is no way out, no maximal answer can be given. Notice also that in the case of questions about individuals a similar problem does not arise and therefore there is no obstacle for there being a maximal answer to these questions. For this reason, we predict the question in (37c) to be acceptable.

It should be noted that given the similarity of selecting a complete answer to definite descriptions, the above account predicts that definite descriptions such as (42) should be also unacceptable:

\#the way in which John didn't behave.

This prediction is indeed borne out. The reason is of course that there is no maximum among the various manners in which John did not behave ${ }^{11}$.

Recall the observation of Fox and Hackl (2007), who have noted that negative islands can be saved by inserting existential modals below negation or by inserting universal modals above negation. These are indeed predicted to be good in our system. Notice that unlike before, we are not talking about a specific event any more, but the event is existentially quantified over. The existential quantification is presumably provided by the existential modal.

[How is John not allowed to behave? $\rrbracket^{\mathrm{w}}$

$$
=\lambda \mathrm{p} . \exists \mathrm{q}_{\text {manner }}\left[\mathrm{p}=\lambda \mathrm{w}^{\prime} \cdot \neg \exists \mathrm{w}^{\prime \prime} \text { Acc }\left(\mathrm{w}^{\prime}, \mathrm{w}^{\prime \prime}\right) \cdot \exists \mathrm{e}\left[\operatorname{behave}\left(\mathrm{w}^{\prime \prime}\right)(\mathrm{e})(\mathrm{J}) \wedge \mathrm{q}_{\operatorname{manner}}\left(\mathrm{w}^{\prime \prime}\right)(\mathrm{e})\right]\right]
$$

Suppose we restricted the domain to the dimension of politeness. As before, the set of alternatives will at least include three contrary predicates: politely, impolitely and neither politely nor impolitely. There is no obstacle in this case for choosing a most informative answer. This is because it might be the case e.g. that impolitely is indeed the only manner in which John is not allowed to behave, and in every other manner he is allowed to behave. In other words the contradiction is resolved by distributing predicates over different worlds and events. Since universal modals above negation are equivalent to existential modals below negation, the same reasoning holds for such examples as well. Further, the same reasoning can also be extended to the fact that attitude verbs above negation also obviate negative islands since attitude verbs are standardly analyzed as involving universal quantification over possible worlds.

\footnotetext{
${ }^{11}$ One might wonder why it is that the examples below do not make the negative manner questions grammatical:

(5) A: *How didn't John behave?

B: Politely, e.g. B': Not politely.

I believe that this apparent problem is in fact part of a larger issue of the impenetrability of the linguistic system for non-linguistic reasoning, or reasoning based on common knowledge. As the requirement of the linguistic system is that there be a most informative true answer to the question, in the rare cases where this leads to a contradiction, we cannot access and recalibrate the rules for the felicity conditions on a question.
} 


\subsection{Negative Islands with Degree Questions and Their Obviation}

The proposal in this section is based on a suggestion made by Benjamin Spector (pc.) to use a degree semantics based on intervals (cf. also Abrusán and Spector 2008). Such an account of degree constructions was originally proposed in Schwarzschild and Wilkinson (2002), and was also adopted (with some modifications) by Heim (2006). The alternative propositions now range over different intervals that could be the argument of the adjective:

(44) $\llbracket$ How tall is John? $\rrbracket^{\mathrm{w}}$

$=\lambda p \cdot \exists I\left[I \in D_{I} \wedge p=\lambda w^{\prime}\right.$. John's height $\in I$ in $\left.w^{\prime}\right]$

'For what interval I, John's height is in I?'

Naturally, there are many intervals for which it is true that John's height (a point) is contained in them. These intervals overlap. I will say that an interval $\mathrm{K}$ covers interval I, if for every degree $\mathrm{d}$ that is an element of I, K contains that element. (In other words, I is a subset of K.) It is easy to see then that the truth of John's height $\in I$, will entail the truth of John's height $\in K$, for every $\mathrm{K}$ that covers I. The most informative answer among the true answers will be the propositin about the smallest interval such that John's height is contained in it. I take it to be a fact of the world that John has some height, therefore there will always be a most informative proposition among the true propositions: that John's height $\in\left\{\mathrm{d}_{\mathrm{j}}\right\}$.

In the case of a negative degree question the situation is different. Given that the entailment pattern is reversed because of negation, if $\mathrm{K}$ covers I, the truth of John's height $\notin K$ entails the truth of John's height $\notin I$. We are then looking for the biggest interval such that John's height is not contained in it. The problem is that there is no such interval.

$$
\begin{aligned}
& \mathbb{I} \text { *How tall isn't John? }]^{w} \\
& =\lambda p . \exists I\left[I \in D_{I} \wedge p=\lambda w ' . \neg \text { John's height } \in\right. \text { I in w'] } \\
& \text { 'For what interval I, John's height is not in I?' }
\end{aligned}
$$

The reason why there cannot be such an interval is because intervals are always convex ${ }^{12}$. The intuitive idea can be illlustrated as follows: Suppose for example that interval $I_{2}$ is wholly below $d_{j}$, while the interval $I_{3}$ is wholly above $d_{j}$. It is easy to see that there is no maximal interval that covers both of these intervals, but does not cover $\mathrm{d}_{\mathrm{j}}$. As long as John has any height in the actual world this situation is in fact unavoidable. Indeed it seems to be a presupposition of degree questions that the answer is not-zero. In the case of asking about John's height this is a trivial fact about the world. In the case of a question such as How many apples did you eat? if no apples were eaten, then a natural answer is the refutation of the presupposition: "I did not eat any apples" instead of rather odd "\#Zero". Notice that for the reasoning outlined above contextually given levels of granularity do not make any difference: any level of granularity will lead to a contradiction, as

\footnotetext{
${ }^{12}$ This assumption, strictly speaking, is more restrictive than Heim (2006) or even Schwarzschild and Wilkinson (2002), for whom intervals could be simply sets of degrees.
} 
long as the domain of degrees contains at least 3 degrees. In other words the scale might be dense (as in the case of heights, e.g.) or discreet (as in the case of children), the ungrammaticality of negative degree questions is equally predicted. This is in contrast with Fox and Hackl (2007)'s account, who need to assume that scales are universally dense.

As we have seen above, certain quantifiers can rescue negative degree questions.:

(46) How much radiation are we not allowed to expose our workers to?

The fact that this question should be grammatical is straightforwardly predicted by the present account: While with respect to (45) it was a fact about the world that John's height is a single degree, the degrees of radiation that we allow our workers to be exposed to might correspond to an interval, e.g. $(0, d]$. Then any interval I wholly above $\mathrm{d}$ is such that it is not allowed the the amount of radiation that we expose our workers be in I. The strongest true proposition of this form is obtained by taking $\mathrm{I}=(\mathrm{d}, \infty)$. Therefore Dayal's $(1996)$ condition can be met.

\subsection{Explicit Domains}

As it was observed by Kroch (1989), negative islands improve if we list potential answers, as shown in the example below:

a. ?How did you not play chess?

A-blindfolded, B-drunk, C-in a bathing suit?

b. Among the following, how many points did Iverson not score?

A-20 B-30 C-40 D-50

It seems that what happens in such cases is that the listed answers in fact facilitate a reading of the question where it ranges over multiple events. This is also argued for by the fact that the question further improves if instead of simple past, the tense of the question is the present perfect, and by inserting a particle such as yet.

(48) How have you not played chess yet?

A-blindfolded B-drunk $\quad \mathrm{C}$-in a bathing suit

Also, notice that if we selected "B" as our answer to (47b) it would imply that there were many events of Iverson scoring. Answer "B" suggests that among the alternatives given, B is the only one to which no scoring event corresponds. Why does evoking multiple events ameliorate negative islands? The reason is very similar to that described in connection with modal obviation. Since contrary predicates can be distributed into different events, the contradiction can be avoided. Further support for this reasoning comes from cases where the multipleevent reading is not easily available. In such cases the listing of answers in fact does not seem to lead to improvement, as shown below: 
(49) a. *How do you not speak French? A: very well B: so-so C: badly

b. \#Among the following, how many children don't you have?
A.2 $\quad$ B. $3 \quad$ C. 4 D. 5

This fact is straightforwardly predicted by the present account, but not by any other account. More generally, unlike what is typically assumed in the syntactic literature, I propose that there is no single phenomenon of "D-linking" that can ameliorate island effects, instead, D-linking can only be understood as cover term for a number of unrelated phenomena: (a) the facilitation of multiple events (as above), (b) scope phenomena (the two readings of how many questions) and (c) identity questions (cf. Section 2.2).

\section{Contradiction and Grammaticality}

The proposal in this paper rests on the claim that the ungrammaticality of weak islands follows from the fact that they lead to a contradiction at some level. In fact we need to distinguish between contradictions that result from non-logical arguments, and contradictions that result from the logical constants alone. Gajewski (2002) argues that the second in fact plays an important role for natural language: sentences that express a contradiction or tautology by virtue of their logical constants are ungrammatical. The present proposal falls under Gajewski's (2002) generalization in that it can be showed that the weak island violations lead to a contradiction due to logical constants alone (cf. discussion in Abrusán 2007).

\section{References}

Abrusán, M. 2007. Contradiction and Grammar: The Case of Weak Islands, Doctoral Dissertation, Massachussetts Institute of Technology.

Abrusán, M. 2008. Presuppositional and Negative Islands: A Semantic Account. Manuscript, Institut Jean Nicod (ENS). available at: http://sites.google.com/site/martaabrusan/

Abrusán, M., and B. Spector. 2008. An Interval Based Semantics for Degree Questions. WCCFL, UCLA, available at http://www.cognition.ens.fr/־bspector/Webpage/wccflAbrusanSpector.pdf.

Chemla, E. 2007. Presuppositions of Quantified Sentences: Experimental Data. Manuscript, ENS.

Dayal, V. 1996. Locality in WH quantification: Kluwer Academic Publishers Boston.

de Swart, H. 1992. Intervention effects, monotonicity and scope. Proceedings of SALT II. CLC Publications, Cornell University, Ithaca.

Fox, D. 2007. Too many alternatives: density, symmetry and other predicaments. Proceedings of SALT XVII.CLC Publications, Cornell University, Ithaca. 
Fox, D., and M. Hackl. 2007. The Universal Density of Measurement. Linguistics and Philosophy 29:537-586.

Gajewski, J. 2002. L-Analyticity in Natural Language. Manuscript, MIT

Gajewski, J. 2005. Neg-raising: polarity and presupposition, Doctoral Dissertation, Massachusetts Institute of Technology.

Guerzoni, E. 2003. Why even ask?: on the pragmatics of questions and the semantics of answers. Doctoral Dissertation, MIT.

Heim, I. 1983. On the projection problem for presuppositions. Proceedings of WCCFL 2:114-125.

Heim, I. 1992. Presupposition Projection and the Semantics of Attitude Verbs. Journal of Semantics 9:183.

Heim, I. 2006. Remarks on comparative clauses as generalized quantifiers. Manuscript. MIT.

Honcoop, M. 1998. Dynamic Excursions on Weak Islands: Holland Academic Graphics.

Horn, L. 1989. A natural history of negation: University of Chicago Press Chicago.

Kiss, K. 1993. Wh-movement and specificity. Natural Language \& Linguistic Theory 11:85-120.

Ko, Heejeong. 2005. Syntax of why-in-situ: Merge into [Spec,CP] in the overt syntax.Natural Language and Linguistic Theory. pp. 867-916.

Kroch, A. 1989. Amount quantification, referentiality, and long wh-movement. Manuscript, University of Pennsylvania.

Kuno, S., and K. Takami. 1997. Remarks on negative islands. Linguistic Inquiry 28:553-576.

Obenauer, H. 1984. On the Identification of Empty Categories. The Linguistic Review 4:153-202.

Oshima, D. 2006. On Factive Islands: Pragmatic anomaly vs. pragmatic infelicity. In New Frontiers in Artificial Intelligence: Joint JSAI 2006 Workshop Post-Proceedings., ed. Ken Saroh et al., Dordrecht: Springer-Verlag.

Rizzi, L. 1990. Relativized Minimality: MIT Press Cambridge, Mass.

Rullmann, H. 1995. Maximality in the semantics of wh-constructions, Doctoral Dissertation, University of Massachusetts, Amherst.

Simons, M. 2001. On the conversational basis of some presuppositions. Proceedings of SALT XI. CLC Publications, Cornell University, Ithaca.

Schlenker, P. 2006. Be Articulate: A pragmatic theory of presupposition projection. Manuscript, UCLA \& Institut Jean-Nicod.

Schwarzschild, R., and K. Wilkinson. 2002. Quantifiers in Comparatives: A Semantics of Degree Based on Intervals. Natural Language Semantics $10: 1-41$

Spector, B. 2005. Aspects de la pragmatique des opérateurs logiques, Doctoral Dissertation, Université de Paris 7.

Szabolcsi, A., and F. Zwarts. 1993. Weak islands and an algebraic semantics for scope taking. Natural Language Semantics 1:235-284.(reprinted in Ways of Scope Taking, ed. A Szabolcsi, Kluwer Academic Publishers, 1997.) 